\title{
Hybrid viability is correlated with the $I$ and $P$ mobile element copy numbers of the maternal inbred line in Drosophila melanogaster
}

\author{
Christian Biémont, \\ Ammaria Aouar, \\ Christian Gautier and \\ Christophe Terzian
}

Laboratoire de Biologie des Populations, Université Lyon 1, 69622 Villeurbanne cedex, France.

Using data from the in situ hybridisation of the giant chromosomes from salivary glands, we have estimated the chromosomal distribution of copia, $m d g-1$ (a copia-like element), $I$ and $P$ (two elements involved in hybrid dysgenesis systems) in hybrids from a $6 \times 6$ diallel cross between highly inbred lines of Drosophila melanogaster. The larvo-pupal viability of the hybrids was found to be significantly correlated with the maternal copy number of the $I$ and $P$ elements. Hybrid viability can thus be predicted from the copy number of certain elements in the maternal inbred lines, and not from the degree of heterozygosity of the hybrid genomes.

\section{INTRODUCTION}

Hybrid vigour has been recognised for decades (see Falconer, 1981; Mather and Jinks, 1971). Its causes, however, are still largely debated, and a means to predict it from morphological, physiological or enzymatic polymorphism characteristics of parental inbred lines is not yet at hand (Gowen, 1952; Falconer, 1981; Lamkey, Hallauer and Kahler, 1987). Indeed, studies of the relationship between the parental and hybrid values ranged from good associations in some cases to poor associations in others. Such discrepancies could result because of sample size, population origin, crossing system, and the environmental conditions in which the lines and the hybrids were tested. However, many authors are of the opinion that a correlation exists between productivity of the parents and that of the hybrids.

On a theoretical ground, it has been postulated that heterosis increases with divergence of the parents, but decreases if the lines are too diverse. Experimentally, there is a general association of allozyme diversity, or degree of heterozygosity, with higher yield (Moll et al., 1965); but this seems reliable only for lines with similar pedigree background (Frei, Stuber and Goodman, 1986), and some specific inbreds deviate from this allozymeyield relationship. Thus, Price et al. (1986) con- cluded that allelic differences at enzyme loci between inbred lines of maize are not useful indicators of the performance of their hybrids. Thanks to the discovery of mobile genomic elements, a new way of assessing genomic diversity is now available. Indeed, mobile genetic elements are found in the genomes of many organisms, and because of their effects on genes and their ability to induce chromosomal rearrangements they are an important source of genetic variability. However, although the structure of these elements is now well known, we have few ideas concerning their effects on organism and the view that they provide no functional benefit to this organism is common place. Their role in inducing mutations as a result of insertion even suggests that they may have an adverse effect on individual fitness, and thus participate in the genetic load (Biémont et al., 1985; Yukuhiro et al., 1985; Fitzpatrick and Sved, 1986; Mackay, 1986). However, experiments in bacteria have shown that the transposons $\operatorname{Tn} 5$ and Tn10 may procure a higher adaptibility to their carriers (Chao et al., 1983; Biel and Hartl, 1983; Hartl et al., 1986), and in Drosophila the number and location of the element $m d g-1$ have been shown to be associated with fitness (Gvozdev et al., 1981; Belyaeva et al., 1982; Biémont et al., 1985). We thus have estimated the chromosomal distribution of copia (Emori et al., 1985), mdg-1 
(a copia-like element; Ilyin et al., 1980; Tchurikov et al., 1981), $I$ and $P$ (two elements involved in hybrid dysgenesis systems; Fawcett et al., 1986; Di Nocera and Casari, 1987; O'Hare and Rubin, 1983) in hybrids from a $6 \times 6$ diallel cross between highly inbred lines of Drosophila melanogaster. The larvopupal viability of the hybrids was found to be significantly correlated with the maternal copy number of the $I$ and $P$ elements.

\section{MATERIALS AND METHODS}

Seventeen inbred lines were initiated from flies randomly taken from a Russian Drosophila population (Biémont and Aouar, 1987); they were maintained by one sib pair every generation. At generation 52, each inbred line was analysed for the number and location of the copia, $m d g-1, I$ and $P$ elements in its genome by in situ hybridization using biotinylated DNA probes on giant chromosomes of salivary glands (see Biémont and Gautier, 1988, for the precise insertion polymorphism of these elements). The DNA was nick-translated with biotinylated 11-dUTP (Rigby et al. 1977 and Langer-Safer, Levine and Ward, 1982), and used in the in situ hybridization technique as previously described (Biémont, 1986). We considered the homozygous inbred lines as a random sample of gametes from individuals of the initial population (Biémont and Gautier, 1987) and we used their insertion patterns to determine those of their hybrids (Biémont and Gautier, 1987, 1988). The experimental analysis of larvae from ten different hybrids has shown that their insertion pattern was actually the addition of patterns of the homozygous parents. We then calculated the theoretical

Table 1 Statistical models used to test the influence of mobile elements on hybrid fitness traits

\begin{tabular}{lll}
\hline Models & Degrees of freedom \\
\hline $\mathrm{A}: \quad V_{i j}=\mu+\varepsilon_{i j}$ & $n(n-1)-1=29$ \\
$\mathrm{~B}: \quad$ or & $=\mu+\alpha \mathrm{m}_{i}+\varepsilon_{i j}$ & $n(n-1)-2=28$ \\
& $V_{i j}=\mu+\beta \mathrm{p}_{i}+\varepsilon_{i j}$ \\
$V_{i j}=\mu_{i, m}+\varepsilon_{i j}$ & \\
$\mathrm{C}: \quad$ or & \\
& $V_{i j}=\mu_{i, p}+\varepsilon_{i j}$ & \\
\hline
\end{tabular}

$V_{i j}=$ viability of the hybrid from lines $i$ and $j$.

$\mu=$ total mean viability of the hybrids.

$\mathrm{m}_{i} ; \mathrm{p}_{i}=$ mobile element copy number of the maternal lines (resp. the paternal lines).

$\mu_{i, m} ; \mu_{i, p}=$ effect of the maternal line $\mathrm{i}$ (resp. the paternal line i).

$\varepsilon_{i j}=$ error terms. numbers of labelled sites (NS), of copies (NC), of heterozygous insertion sites $(\mathrm{NH})$, and the degree of heterozygosity $(\mathrm{H}=\mathrm{NH} / \mathrm{NS})$ for each mobile element and for each hybrid genome (Biémont and Gautier, 1987, 1988). In 30 experimental hybrids, produced from crossing six inbred lines of generation 53, we determined the hatchability rate of six batches of 50 eggs per cross and the larvo-pupal viability. Each batch of 50 eggs was taken from the eggs laid by a group of ten flies (five males of a given line and five females of a different line); all tests were carried out in a contemporary experiment. We did not take into account the proportion of non fertilized eggs since this is more a characteristic of the maternal inbred line used than of the hybrid genome.

\section{RESULTS AND DISCUSSION}

To test the influence of the mobile element copy numbers of paternal and maternal lines on hybrid viability and egg-hatchability, we compared three different models by analyses of variance (see table 1). Comparison of the models A and B allowed a linear effect of the number of mobile elements contained in the maternal lines to be tested. A general maternal effect, without any reference to mobile element, was tested by comparing the model $C$ vs. A, the result being of course mathematically independent of the mobile element considered. The comparison of $\mathrm{C}$ vs. $\mathrm{B}$ tested the existence of a maternal effect not explained by the linear relationship with the maternal mobile element copy number. As seen in table 2, a classical maternal effect was detected on larvo-pupal viability. We show here that it was due in part to the mobile element copy number of the maternal lines. This latter effect was statistically significant only for the two elements $I$ and $P$. As an example, the influence of the $I$ element copy number of the maternal lines on the hybrid viability is represented in fig. 1. We did not find any kind of effect of the

Table $2 F$ values: comparison between the models of Table 1 applied to hybrid larvo-pupal viability and mobile element copy number. For the models $\mathrm{A}, \mathrm{B}$ and $\mathrm{C}$, see table 1

\begin{tabular}{llccc}
\hline & \multicolumn{4}{c}{ Mobile elements } \\
\cline { 2 - 5 } Models & $m d g-1$ & copia & $I$ & $P$ \\
\hline B vs. A & $3 \cdot 4$ & $1 \cdot 8$ & $23 \cdot 0^{* *}$ & $14 \cdot 3^{* *}$ \\
C. vs. B & $8 \cdot 7^{* *}$ & $9 \cdot 4^{* *}$ & $3 \cdot 0^{*}$ & $4 \cdot 9^{* *}$ \\
C vs. A & $8 \cdot 7^{* *}$ & $8 \cdot 7^{* *}$ & $8 \cdot 7^{* *}$ & $8 \cdot 7^{* *}$ \\
\hline
\end{tabular}

** $P<0.01 ; * P<0.05$ 

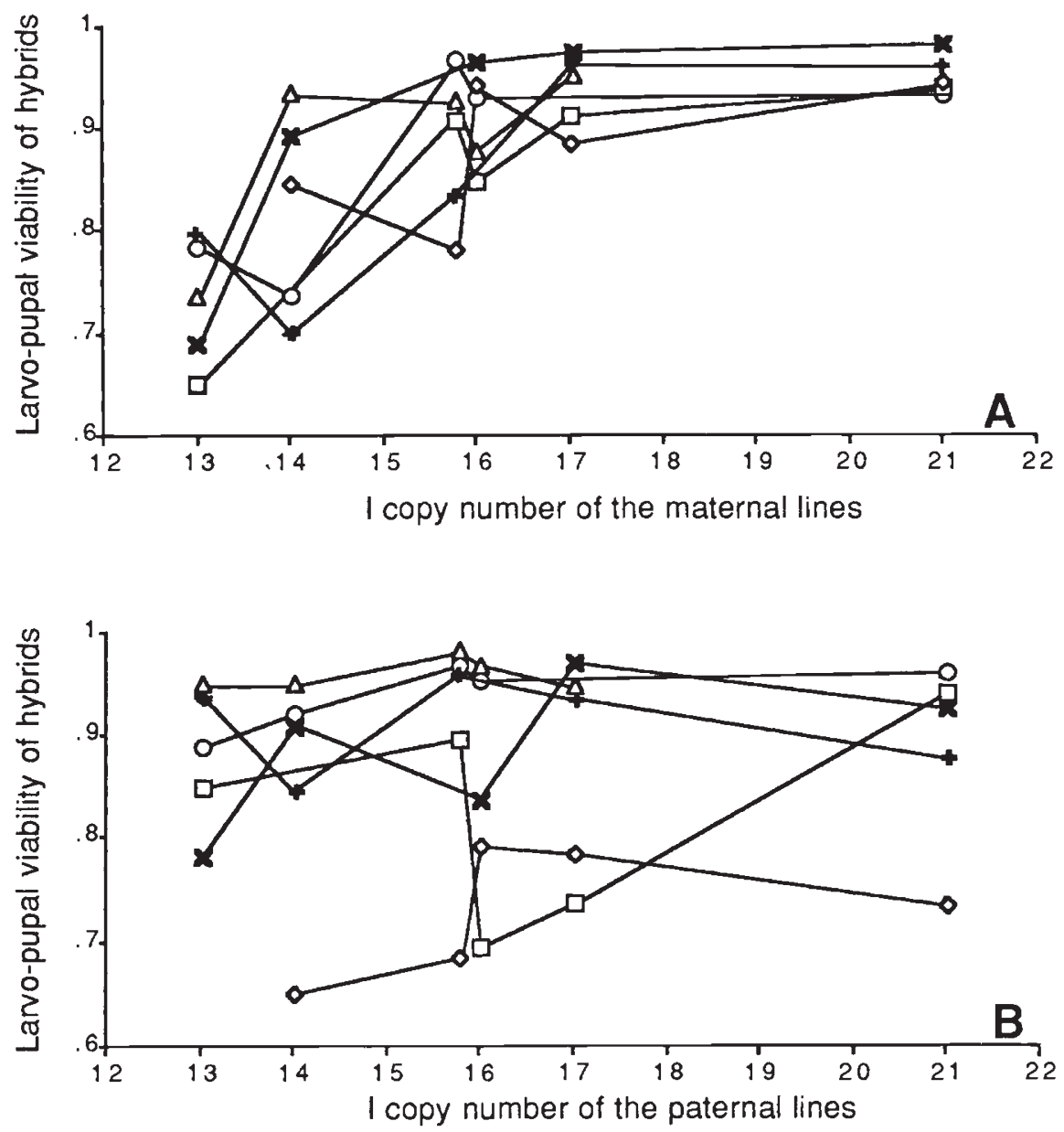

Figure 1 The relationship between larvo-pupal viability of hybrids from the $6 \times 6$ diallel cross and the $l$ element copy number in (A) the maternal inbred lines, (B) the paternal inbred lines. The same symbol is used for the male (fig. A) and the female (fig. B) of a given inbred line.

paternal lines (see fig. 1B and table 2) on hybrid viability (all the $F$ values were below 1 ).

The above observation suggests, in agreement with a recent report (Biémont and Terzian, 1986), that some cytoplasmic factor(s) depending on mobile element copy number may interfere with larvo-pupal viability. Moreover, no correlation was found between the viability values of the hybrids and those of their parental inbred lines. Hence, the copy number of the $I$ and $P$ elements in the maternal line was a key factor in determining the viability values of a given hybrid.

We did not find any clear relationship for hybrid egg-hatchability values. However, these values were generally high except for the hybrids with low mobile element copy number; these latter hybrids also had a low egg production (data not shown).
Classically, using enzymatic data (Gowen, 1952; Falconer, 1981; Lamkey, Hallauer and Kahler, 1987), attempts have been made to associate hybrid vigour with genomic heterozygosity. Hence, we searched for a relationship between the hybrid viability values and the degree of heterozygosity NH/NS (Biémont and Gautier, 1987, 1988); no such correlation was found. Moreover, we did not find any correlation between the four mobile element families for the heterozygosity levels of the hybrids; thus one mobile element does not give a precise idea of the overall genome heterozygosity. This may of course be due to the fact that we worked with hybrids from crosses between highly inbred lines. Such hybrids may differ from random mating individuals because their genome is not stabilized by any kind of mating system cycle and natural selection. Further crosses could reset their 
genome for mobile element insertion polymorphism, thus leading to individuals in which the degrees of heterozygosity for various mobile elements could be correlated. It may be, however, that the genome is not homogeneous and that its degree of heterozygosity depends on the mobile element family. In such cases, it is quite confusing to calculate the degree of heterozygosity by lumping together various elements in a single ensemble, as incorrectly done many times with enzymatic data (see Lewontin, 1985 for a discussion).

Genetic diversity measured in terms of mobile elements is thus not a good estimate of the actual heterozygosity of the entire individual genome (in the hypothesis that this total heterozygosity has a real meaning), and the divergence among lines, measured by this approach, may not reflect the potential divergence determined from enzymatic polymorphism. Because of transposition, recombination, copy number regulation and genome reshuffling (Biémont, Aouar and Arnault, 1987), the genome may indeed encounter some changes independent of the enzymatic locus background. This could shed new light on the divergent relationships reported between enzymatic heterozygosity and morphological or physiological characteristics (Frei, Stuber and Goodman, 1986; Strauss, 1986). These relationships have been widely debated, but there is still no consensus as to what kind of genes or how many loci, can actually give a good indication of the heterozygosity of the genome.

It is puzzling that only the $I$ and $P$ elements were involved in the association with hybrid viability while the $m d g-1$ and copia elements were not. Indeed, these two elements are the transposons implied in the so-called $I / R$ and $P / M$ systems of hybrid dysgenesis (Brégliano and Kidwell, 1983). Various effects of dysgenesis are observed in progeny of crosses between a male from an $I$ strain (containing $I$ elements) or a $P$ strain (containing full-length $P$ elements) and a female from an $R$ or an $M$ strain; and there is no effect of reciprocal crosses, which implies that specific cytoplasmic and chromosomal interactions are the underlying cause of the hybrid dysgenesis phenomenon. The $I$ and $P$ elements are mobilized under the conditions of dysgenesis. In the $P / M$ system, there also exist $M^{\prime}$ strains which contain sequences homologous to $P$ elements, a few of which may be full length but most of which are defective and nonautonomous as a result of truncation by internal deletion (see Snyder and Doolittle, 1988). As far as these two systems are concerned, the six lines used in our study were $I$ and $M^{\prime}$ strains (Ronsseray, personal communication; and see
Biémont and Gautier, 1988, for chromosomal location of the $I$ and $P$ elements). Hence, no manifestation of hybrid dysgenesis was to be expected by intercrossing these lines. There is thus no evident reason to associate hybrid vigour (which results from intra-strain crosses) with hybrid dysgenesis manifestations (which result from inter-strain crosses). It remains that some specific cellular processes involved in the $I / R$ and $P / M$ dysgenesis systems may also contribute to viability values of organisms not submitted to dysgenic conditions.

The relationship between viability value and mobile element copy numbers agrees well with some other observations (Biémont and Terzian, 1986; Belyaeva et al., 1982), but is inconsistent with recent theoretical considerations which posit that if copy number is controlled by natural selection then individual fitness should decrease as copy number increases (Charlesworth and Charlesworth, 1983). If the above association between the maternal set copy number of some mobile elements and some fitness components is confirmed, mobile elements will be central to further detailed analysis of the differential activation of maternal and paternal loci during development, the way cytoplasmic factors may control gene expression (Wolf and Rimpau, 1977) and development of progeny (Visscher, 1971). Transposable elements may thus help towards a better understanding of the fine structure of the genome and hence population adaptation and evolutionary processes.

Acknowledgements We thank C. Arnault, C. Loevenbruck for comments, and A. Heizmann for technical assistance. This work was supported by the Centre National de la Recherche Scientifique (U.A. 243), the Association pour la Recherche sur le Cancer, and the Fondation pour La Recherche Médicale.

\section{REFERENCES}

BFLYAEVA, F. SP., PASYUKOVA, E. G., GVOZDEV, V. A.. II.YIN Y. V. ANI KAIDANOV. I. Z. 1982. Transpositions of mobile dispersed genes in Drosophila melanogaster and fitness of stocks. Mol. Gen. Genet., 185, 324-328.

BIEL, S. W. AND HARTL, I). L. 1983. Evolution of transposons: natural selection for Tn5 in Escherichia coli K12. Genetics, $103,581-592$.

BIEMONT, C. 1986. Polymorphism of the $m d g-1$ and $I$ mobile elements in Drosophila melanogaster. Chromosoma, 93, $393-397$

BIÉMONI, C. AND AOUAR, A. 1987. Copy-number dependent transpositions and excisions of the $m d g-1$ mobile element in inbred lines of Drosophila melanogaster. Heredity, 58, 39-47.

BIÉMONT, C., AOUAR, A. AND ARNAIIT, C. 1987. Genome reshuffing of the copia element in a Drosophila melanogaster inbred line. Nature, 329, $742-744$. 
BIÉMONT, C., BELYAEVA, E. SP., PASYUKOVA, E. F. AND KOGAN, G. 1985. Mobile gene localisation and viability in a natural population of Drosophila melanogaster. Experientia, 41, 1474-1476.

BIÉmont, C. AND GAUTIER, C. 1987. Mdg-1 mobile element heterozygosity in Drosophila melanogaster. Heredity, 58, $167-172$.

BIÉMONT, C. AND GAUTIER, C. 1988. Localization polymorphism of $m d g-1$, copia, $I$ and $P$ mobile elements in genomes of Drosophila melanogaster, from data of inbred lines. Heredity, 60, 335-346.

BIÉMONT, C. AND TERZIAN, C. 1986. Regulation in the number of mdg-1 mobile elements in inbred Drosophila melanogaster. Genetica, 71, 161-165.

BRÉGLIANO, J. C. AND KIDWELL, M. G. 1983. Hybrid dysgenesis determinants. In Shapiro, J. A. (ed.) Mobile Genetic Elements, Academic Press.

CHAO, L., VARGAS, C., SPEAR, B. B. ANU COX, E. C. 1983. Transposable elements as mutator genes in evolution. Nature, 303, 633-635.

CHARLESWORTH, B. AND CHARLESWORTH, D. 1983. The population dynamics of transposable elements. Genet. Res., 42, $1-27$.

DI NOCERA, P. P. AND CASARI, G. 1987. Related polypeptides are encoded by Drosophila $F$ elements, $I$ factors, and mammalian L1 sequences. Proc. Natl Acad. Sci. USA, 84, 5843-5847

EMORI, T., SHIBA, T., KANAYA, S., INOUYE, S., YUKI, S. AND SAIGO, K. 1985. The nucleotide sequences of Copidrelated RNA in Drosophila virus-like particles. Nature, $315,773-776$.

FALCONER, D. S. 1981. Introduction to Quantitative Genetics, 2nd edn, Oliver \& Boyd, Edinburgh.

FAWCETT, D. H., LISTER, C. K. KELLET, E. AND FINNEGAN, D. J. 1986. Transposable elements controlling $I$ - $R$ hybrid dysgenesis in $D$. melanogaster are similar to mammalian LINEs. Cell, 47, 1007-1015.

FITZPATRICK, B. J. AND SVED. J. A. 1986. High levels of fitness modifiers induced by hybrid dysgenesis in Drosophila melanogaster. Genet. Res., 48, 89-94.

FREI, B., STUBER, C. W. AND GOODMAN, M. M. 1986. Use of allozymes as genetic markers for predicting performance in maize single cross hybrids. Crop Science, 26, 37-42.

Gowen, J. w. 1952. Heterosis. Gowen, J. (ed.) Iowa State Coll. Press, Ames, Iowa.

GVOZDEV, V. A., BELYAEVA, E. SP., ILYIN, Y. U., AMOSOVA, 1. S. AND KAIDANOV, L. Z. 1981. Selection and transposition of mobile dispersed genes in Drosophila melanogaster. Cold Spring Harbor Symp. Quant. Biol., 45, 673-685.

HARTL, D. L., MEDHORA, M. GREEN, L. AND DYKHUIZEN, D. E. 1986. The evolution of DNA sequences in Escherichia coli. Phil. Trans. R. Soc. London, 312, 191-204.

ILYIN, Y. V., CHMELIAUSKAITE, V. G. ANI GEORGIEV, G. P. 1980. Double-stranded sequences in RNA of Drosophila melanogaster: relation to mobile dispersed genes. Nucleic Acid Res., 8, 3439-3457.
LANGER-SAFER, P. R., LEVINE, M. AND WARD, D.C. 1982. Immunological method for mapping genes on Drosophila polytene chromosomes. Proc. Natl Acad. Sci. USA, 79, 4381-4385.

LAMKFy, K. K., HAllaueR, A. R. AND KAHLER, A. L. 1987. Allelic differences at enzyme loci and hybrid performance in maize. $J$. Heredity, 78, 231-234.

LEWOntin, R. C. 1985. Population genetics. Ann. Rev. Genet. $19,81-102$.

MACKAY, T. F. C. 1986. Transposable element-induced fitness mutations in Drosophila melanogaster. Genet. Res., 48, $77-87$.

MATHER, K. AND JINKS, J. L. 1971. Biometrical Genetics. Chapman and Hall, London.

MOLL, R. H., LONNQUIST, J. H., VÉLEZ FORTUNO, J., AND JOHNSON, E. C. 1965. The relationship of heterosis and genetic divergence in maize. Genetics, 52, 139-144.

O'HARE, K. AND RUBIN, G. M. 1983. Structures of P transposable elements and their sites of insertion and excision in the Drosophila melanogaster genome. Cell, 34, 25-35.

PRICE, S. C., KAHLER, A. L., HALlAuER, A. R., CHARMLEy, P., AND GIEGEL, D. A. 1986. Relationships between performance and multilocus heterozygosity at enzyme loci in single cross hybrids of maize. $J$. Hered., 77, 341-344.

RIGBY, P. W., DIECKMANN, M., RHODES, C. AND BERG, P 1977. Labeling dexoyribonucleic acid to high specific activity in vitro by nick translation with DNA polymerase I. J. Mol. Biol., 113, 237-251.

SNyder, M. AND DOOlitTle, W. F. 1988. $P$ elements in Drosophila: selection at many levels. Trends in Genet., 4 147-149.

STRAUSS, S. H. 1986. Heterosis at allozyme loci under inbreeding and crossbreeding in Pinus attenuata. Genetics, 113 , 115-134.

TCHURIKOV, N. A., ILYIN, Y. V, SKRYABIN, K. G., ANANIEV, E. V., BAYEV, A. A., KRAYEV, A. S. ZELENTSOVA, E. S., KULGUSKIN, V. V., LYUBOMIRSKAYA, N. V. AND GEORGIEV, G. P. 1981. General properties of mobile dispersed genetic elements in Drosophila. Cold Spring Harbor Symp. Quant. Biol., 45, 655-665.

VISSCHFR, S. N. 1971. Studies on the embryogenesis of Aulocara elliotti (Orthoptera, Acrididae). III Influence of maternal environment and ageing on development of the progeny. Annu. Entomol. Soc. Amer., 64, 1057-1074.

WOLF, G. AND RIMPAU, j. 1977. Evidence for cytoplasmic control of gene expression in higher plants. Nature, 265 , $470-472$.

YUKUHIRO, K., HARADA, K. AND MUKAI, T. 1985. Viability mutations induced b.y the $\mathrm{P}$ elements in Drosophila melanogaster. Jap. J. Genet., 60, 531-537. 